\title{
A novel compact reactor for three-phase hydrogenations
}

\author{
Martin Grasemann, Albert Renken, Madhvanand Kashid, Lioubov Kiwi-Minsker* \\ Group of Catalytic Reaction Engineering (GGRC-ISIC-SB), Ecole Polytechnique Fédérale de Lausanne (EPFL), CH H3 584, Station 6, CH-1015 Lausanne, Switzerland
}

\section{A R T I C L E I N F O}

\section{Article history:}

Received 6 July 2008

Received in revised form 10 June 2009

Accepted 17 June 2009

Available online 30 June 2009

\section{Keywords:}

Intensification of selective hydrogenation

Staged bubble column reactor

Micro-heat-exchanger

$\mathrm{Pd} / \mathrm{ZnO}$ structured catalyst

2-methyl-3-butyn-2-ol

\begin{abstract}
A B S T R A C T
A novel reactor based on a bubble column staged by structured catalytic layers with integrated cross flow micro-heat-exchangers (HEX) was designed and tested in the solvent free hydrogenation of 2-methyl3-butyn-2-ol (MBY) aiming on process intensification. The heat transfer performance of the HEX was determined for both single- and two-phase flow. The reaction side heat transfer coefficient was found to decrease considerably when gas was added to the feed stream. Similar to single-phase conditions, the heat transfer coefficient increased linearly with gas and liquid superficial velocity, $u_{0, G}$ and $u_{0, L}$. Change from water to organic media decreased heat transfer in HEX element and the influence of $u_{0, G}$ and $u_{0, L}$ diminished.

The HEX integrated within a staged bubble column reactor (SBCR) with catalytic layers made of Pd/ZnO on sintered metal fibers showed a high specific productivity in the solvent free hydrogenation of MBY. Despite the observed influence of external mass transfer on the overall catalyst performance, the SBCR productivity was several orders of magnitude above the values obtainable in conventional multiphase reactors.
\end{abstract}

(c) 2009 Elsevier Ltd. All rights reserved.

\section{Introduction}

Catalytic selective hydrogenation of organic molecules ranges among the most important reactions in the production of fine chemicals and pharmaceuticals. The performance of the hydrogenation process is strongly dependent on the catalyst activity/selectivity and the interaction of chemical kinetics with mass transfer in the eventual reactor. To avoid internal and external mass transfer limitations and to attain high product yield and selectivity, catalyst particles in the micrometer range are required leading to the use of suspension reactors. The most common reactors are batch-wise operated slurry reactors like stirred tanks and loop reactors. While mass transfer characteristics would call for even smaller particles, the minimal size of the catalyst particles, however, is limited due to catalyst handling like solids charging, filtration and discharging that often pose safety and environmental problems (Roessler, 2003).

Due to the above mentioned limitations of slurry systems, considerable efforts have been dedicated to the application of structured catalytic materials for multiphase hydrogenation processes. Besides the avoided problems of catalyst handling, the main advantage of these reactors is that the catalyst structure can be designed over

\footnotetext{
* Corresponding author. Tel.: +41216933182, Secretary: +41216933145; fax: +41216936091 .

E-mail address: lioubov.kiwi-minsker@epfl.ch (L. Kiwi-Minsker).
}

multiple levels meeting the system requirements (Kreutzer et al., 2006). In recent years various studies have shown the superiority of structured catalytic beds over conventional slurry hydrogenation technology in terms of mass transfer, product selectivity and productivity (Cybulski et al., 1999; Höller et al., 2001; Nijhuis et al., 2001; Kiwi-Minsker et al., 2004).

Another important aspect of reactor design is related to the evacuation of process heat since hydrogenations are highly exothermic reactions. Especially in solvent free applications the maximum adiabatic temperature rise can exceed $600 \mathrm{~K}$ making temperature control important for process safety and product selectivity. In conventional slurry reactors this is usually achieved by adding an external loop with heat-exchanger and by limiting the amount of catalyst up to $\sim 5 \mathrm{wt} \%$. This reduces the heat production but affects reactor performance.

Monolith reactors are considered as adiabatic (Kreutzer et al., 2006) and have been applied with recycling through external heatexchanger. This allows sufficient process temperature control, but gives total backmixing of reaction products (Kreutzer et al., 2006). In complex reaction systems, like the selective hydrogenation of alkynes with the alkene as the target product, complete backmixing leads to considerable losses in product yield at high conversions, often outweighing the above mentioned improvements. In addition, the reactor volume should be kept small for safety reasons. This is of crucial importance if unstable intermediates (e.g. azides) have to be hydrogenated. Therefore, novel designs of compact reactors for continuous operation with efficient evacuation of reaction heat and presenting plug flow behavior are warranted. 
The present work is aimed on the development of a novel compact reactor for continuous three-phase hydrogenation based on structured catalytic bed. The reactor design includes a bubble column staged with fibrous catalytic layers (Höller et al., 2001; Kiwi-Minsker et al., 2004) and micro-heat-exchangers. The feasibility of the developed reactor is demonstrated for the selective hydrogenation of pure (solvent free) 2-methyl-3-butyn-2-ol (MBY) to 2-methyl-3-buten-2ol (MBE) (Fig. 1).

\section{Reactor concept, design and fabrication}

Recently we suggested fibrous catalysts in the form of sintered metal fibers (SMF) integrated in a staged bubble column reactor (Grasemann et al., 2007). As the diameter of a single fiber is in the micrometer range, internal and external liquid/solid mass transfer limitations can be effectively avoided, while the open macrostructure of the SMF material gives a low pressure drop during the passage of fluids. It also helps for micro-mixing and enhances bubble redistribution on each stage. The SMF layers are made of FeCrAl alloy

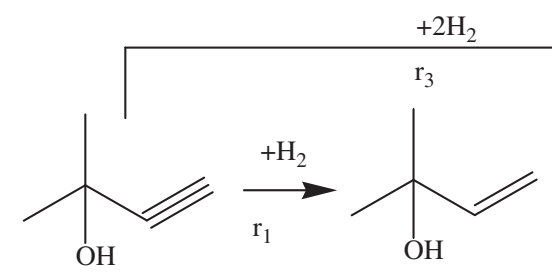

2-methyl-3-butyn-2-ol 2-methyl-3-buten-2-ol

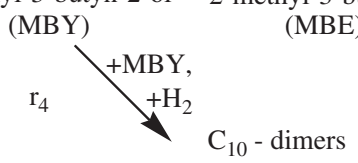

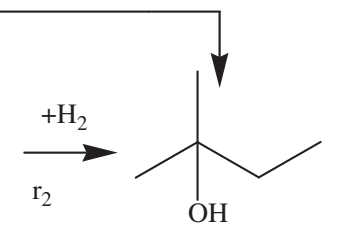

2-methylbutan-2-ol (MBA)
Fig. 1. Reaction scheme of 2-methyl-3-butyn-2-hydrogenation. in the form of uniform porous panels $(0.29 \mathrm{~mm}$ thick, $71 \%$ porosity, $675 \mathrm{~g} \mathrm{~m}^{-2}$, ca. $20 \mu \mathrm{m}$ fiber diameter). The coating of the SMF surface with $\mathrm{Pd} / \mathrm{ZnO}$ was carried out according to a procedure described elsewhere (Semagina et al., 2007, 2008), yielding a homogeneous catalytic coating of approximately $1.5 \mu \mathrm{m}$ thickness (Fig. 2c).

Due to the variable distance between catalyst layers, staged bubble column reactors (SBCR) can be easily adjusted to process requirements in catalyst loading, reactor volume and phase mixing intensity. Therefore, integrated heat-exchange (HEX) elements were designed to be placed between adjacent catalyst layers within the bubble column, forming an integral unit of a reactor stage. Thus, reaction heat produced in each catalyst layer is directly evacuated in the adjacent upstream heat-exchange element. Fig. 2a shows a setup scheme containing a 10-staged bubble column reactor with integrated cooling elements (Fig. 2b).

To keep the compactness of the SBCR, the HEX element has to present a minimal additional reaction volume and at the same time provide high heat-exchange performance. To meet these requirements, the HEX was designed as vertical micro-slits cut through a circular stainless steel plate of $7 \mathrm{~mm}$ thickness and an outer diameter of $56 \mathrm{~mm}$. One element contains 17 slits of $300 \mu \mathrm{m}$ width, cut though the plate at equal distances of $2.4 \mathrm{~mm}$ over the internal reactor cross section $\left(D_{\mathrm{SBCR}}=40 \mathrm{~mm}\right)$ diameter. Horizontal cooling

Table 1

Design parameters of the micro-heat-exchanger.

\begin{tabular}{lll}
\hline Design parameters & Units & Value \\
\hline Internal column diameter, $D_{\mathrm{SBCR}}$ & $\mathrm{m}$ & 0.04 \\
Number of heat transfer slits per element, $N$ & - & 17 \\
Total cooling channel/slit length, $l$ & $\mathrm{~m}$ & 0.53 \\
Total heat transfer area (reaction side), $A_{R}$ & $\mathrm{~m}^{2}$ & $7.74 \times 10^{-3}$ \\
Total heat transfer area (cooling water side), $A_{\mathrm{CW}}$ & $\mathrm{m}^{2}$ & $1.67 \times 10^{-3}$ \\
Total free volume (reaction side), $V_{R}$ & $\mathrm{~m}^{3}$ & $3.69 \times 10^{-3}$ \\
Relative free volume, $V_{R} / V_{\text {tot }}$ & $\%$ & 39 \\
\hline
\end{tabular}

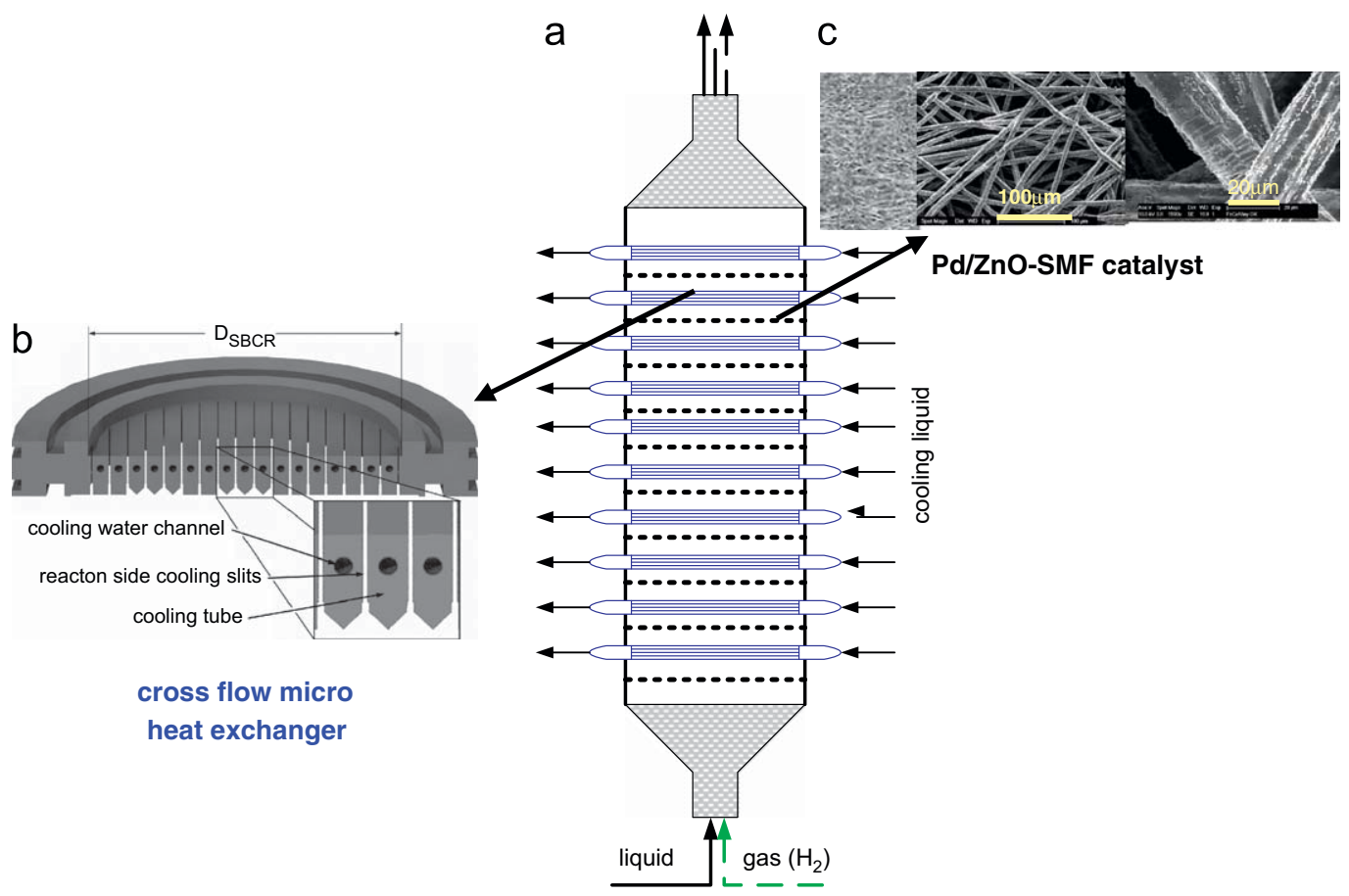

Fig. 2. (a) Staged bubble column reactor (SBCR) with integrated catalyst layers and micro-heat-exchanger; (b) vertical cut through the heat-exchanger element and (c) $\mathrm{Pd} / \mathrm{ZnO} / \mathrm{SMF}$ catalyst. 


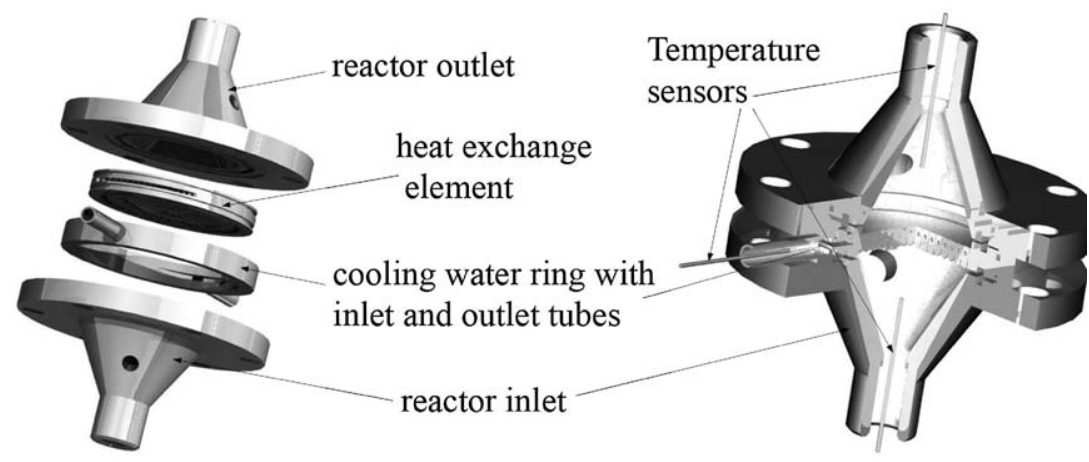

Fig. 3. Assembly drawing of the one-stage heat-exchanger setup.

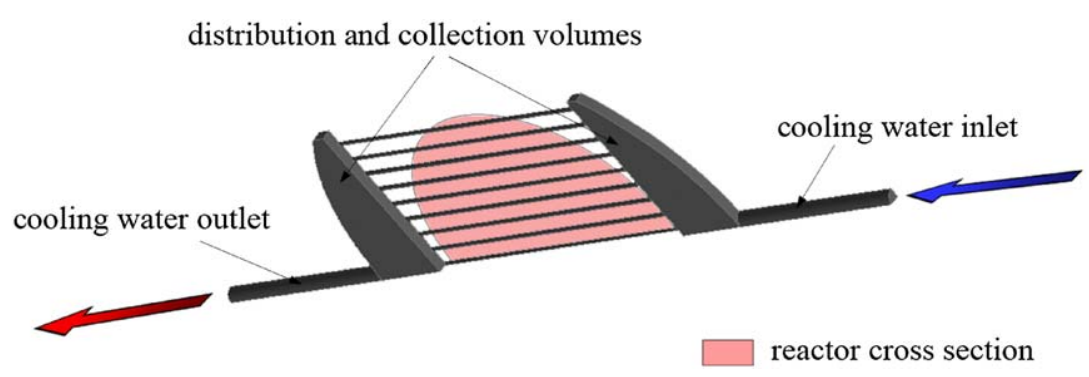

Fig. 4. Schematic representation of the geometry used for cooling water flow simulations.

water channels of $800 \mu \mathrm{m}$ diameter were subsequently drilled through the remaining parallel bars. The result is a stack of cooling tubes of equal length aligned horizontally at a distance of $300 \mu \mathrm{m}$, forming a micro-heat-exchanger stage with cross flow configuration. Fig. $2 \mathrm{~b}$ shows a vertical cross section through the resulting element geometry of the stainless steel HEX. This design combines low volume with small heat transfer distances. The main dimensions and design parameters of the micro-HEX are summed up in Table 1.

While the reaction side cooling slits extended only to the perimeter of the reactor cross section, therefore varying in width, the cooling water channels were all of equal length, partly extending into the surrounding material. The channel outlets and inlets were connected to segmental cooling water distribution volumes of $1 \mathrm{~mm}$ height cut from the main element body material. To connect these cooling water distribution volumes to the cooling water supply, the central HEX element was inserted into a stainless steel ring comprising cooling water in- and outlet tubes. The ring was aligned to the heat exchange element and held in place by two o-rings to seal the cooling water system. An assembly drawing of the reactor setup with ring and HEX-element is shown in Fig. 3, left.

A homogeneous distribution of cooling water over 17 channels is of vital importance to keep local differences in cooling rate and heat transfer as small as possible. As the flow distribution was not experimentally accessible, a numerical simulation of the fluid flow through the cooling water system was done. The Reynolds number of the cooling water flow in the inlet and outlet of the HEX-element was 11,745 , which corresponds to a value of 3872 in the cooling water channels. Based on these high Reynolds number values, a standard $k-\varepsilon$ turbulence simulations were carried out using commercial CFD code Fluent (Fluent Inc.). Solving turbulence at very refined mesh requires large amount of computational resources therefore only one quarter of the cooling system geometry was used as computational domain assuming flow symmetry (Fig. 4). All relevant simulation
Table 2

Summary of CFD simulation parameters.

\begin{tabular}{ll}
\hline Used package and version & $\begin{array}{l}\text { Fluent } 6.3 .26 \text { and Gambit } 2.4 \\
\text { Flow type }\end{array}$ \\
Viscosity model & $\begin{array}{l}\text { Standard } k-\varepsilon \text { turbulence with enhanced } \\
\text { wall treatment }\end{array}$ \\
Medium & Water \\
Mass flow & $0.0104 \mathrm{~kg} \mathrm{~s}^{-1}$ (one quarter of $Q_{m}=0.0416 \mathrm{~kg} \mathrm{~s}^{-1}$ ) \\
$\begin{array}{l}\text { Reynolds number } \\
\text { Inlet and outlet }\end{array}$ & 11,745 \\
Cooling water channel & 3872 \\
Inlet & Mass flow inlet \\
Outlet & Pressure outlet \\
Geometry and mesh & One quarter of model geometry, 1,021,968 cells \\
Mesh type & Reaction channels: cooper; other parts: \\
& tetrahedron hybrid \\
\hline
\end{tabular}

parameters are listed in Table 2. The velocity field obtained from the simulation as shown in Fig. 5 indicates only a minor flow rate maldistribution between cooling channels.

\section{Experimental setup and procedure}

\subsection{Heat transfer}

The reactor setup used to characterize the heat transfer performance of one heat exchanger element is shown in Fig. 3, right. The conical entrance and exit sections were filled with $1 \mathrm{~mm}$ glass beads to provide even flow distribution at the reactor entrance and to minimize response time to flow rate variations during measurements.

Inlet and outlet temperatures of both cooling water and reaction side fluids were measured using Pt100 sensors positioned inside the conical entrance and exit regions of the reactor and inside the cooling water in- and outlet tubes, respectively. The exact positions of the 
a

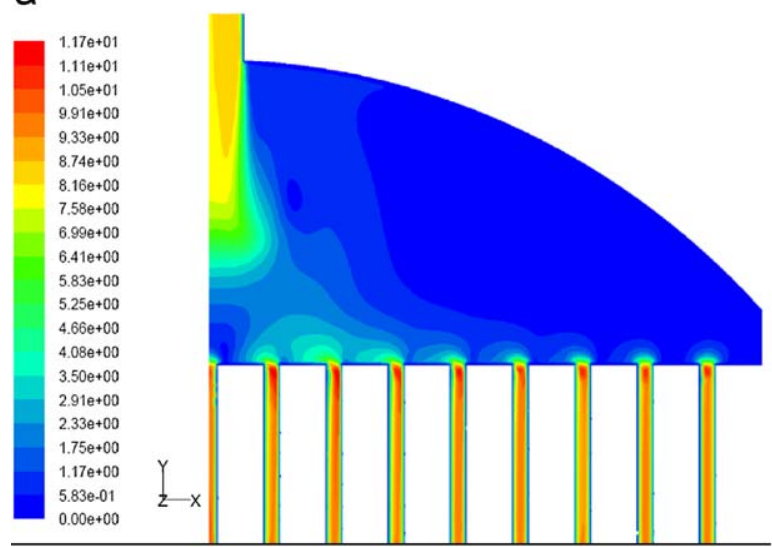

b

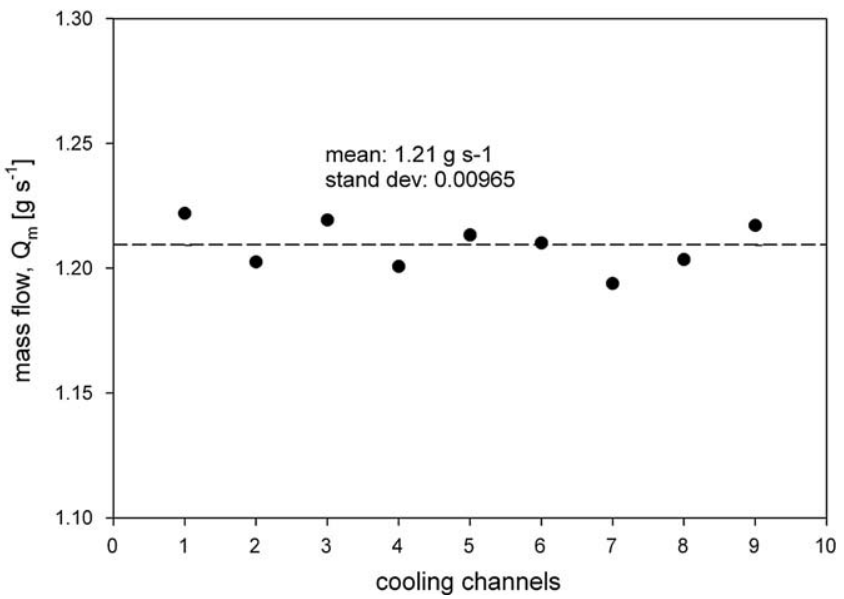

Fig. 5. CFD simulation results: (a) velocity field in the cooling water system (see Table 2) and (b) resulting flow distribution.

Table 3

Experimental conditions summary.

\begin{tabular}{llll}
\hline System & Catalyst & $\begin{array}{l}\text { Gas superficial } \\
\text { velocity } u_{0, G} \\
\left(\mathrm{~cm} \mathrm{~s}^{-1}\right)\end{array}$ & $\begin{array}{l}\text { Liquid superfi- } \\
\text { cial velocity } u_{0, L} \\
\left(\mathrm{~cm} \mathrm{~s}^{-1}\right)\end{array}$ \\
\hline Water & - & - & $1.3-6.0$ \\
Water/air & - & $6.7-25.4$ & $0.8-7.5$ \\
Water/air & $5 \mathrm{wt. \%} \mathrm{ZnO} / \mathrm{SMF}$ & $6.7-25.4$ & $0.8-7.5$ \\
Organic solvent/N2 & $5 \mathrm{wt. \%} \mathrm{ZnO} / \mathrm{SMF}$ & $8.5-31.0$ & $0.8-10.1$
\end{tabular}

Values for $u_{0, G}$ are given at $T_{R}$ and $p_{R}$.

temperature sensors are marked in Fig. 3, right. All Pt100 sensors were cross-calibrated at 0 and $100^{\circ} \mathrm{C}$, leading to a relative accuracy of $\pm 0.05 \mathrm{~K}$

The whole reactor setup was insulated in 30-60 mm EPDM foam (Aeroflex ${ }^{\circledR}$ ), reducing heat losses. The system pressure was measured at the reactor outlet using a piezoelectric pressure sensor (Keller, Germany).

For the experiments with structured catalyst, one layer of SMF catalyst was clamped between bubble column entrance section and the HEX element.

Gas and liquid passed through the setup in cocurrent upflow. Reaction side liquid flow rates were controlled using precision gear pumps (Ismatec, USA); gas flow rates were set using a rotameter (Vögtlin, Switzerland) and measured downstream using a bubble flow meter at ambient conditions. The cooling water flow rate was kept constant at $2.5 \mathrm{~L} \mathrm{~min}^{-1}$ for all experiments to minimize the cooling water temperature increase in the slit-HEX. The resulting cooling water channel Reynolds number was calculated as 3600 , based on the viscosity of $1.3 \times 10^{-3}$ Pas (water at $10^{\circ} \mathrm{C}$ ) and a flow velocity of $\sim 5.9 \mathrm{~m} \mathrm{~s}^{-1}$.

The cooling water and reactor inlet temperatures were controlled using circulating bath thermostats (Huber, Germany).

The heat transfer performance of the micro-HEX element was determined for the configurations and gas-liquid combinations listed in Table 3. Gas superficial velocities are in all cases given as values at actual reactor temperature and pressure.

The experimental program for each $G-L$ combination comprised a $2^{2}$ central composite experimental design with gas and liquid superficial velocities as design factors (Box et al., 2005).

For each gas-liquid flow rate combination of the experimental design, temperature and pressure data were averaged over $5 \mathrm{~min}$ after a stabilization period of $25 \mathrm{~min}$.

\subsection{Continuous hydrogenation on 2-methyl-3-butyn-2-ol}

The performance of the SBCR reactor with integrated micro-heatexchanger was determined for the solvent free hydrogenation of 2-methyl-3-butyn-2-ol, using a high pressure loop setup with the reactor shown in Fig. 3 as central reactor unit. The set-up corresponds to the installation presented by Kiwi-Minsker et al. (2004). The solvent free liquid reactant was fed to the reactor using an HPLC pump (Gilson, France). Reaction pressure was set using a pressure reduction valve in the hydrogen supply line. Reaction temperature was controlled adjusting the cooling water temperature using a thermostat (Huber, Germany) with the reactor outlet temperature as external control variable.

The off-gas was separated from excess liquid product in a gas-liquid separator. The gas was cooled down to $-15^{\circ} \mathrm{C}$ at ambient pressure to separate remaining organic vapor.

Liquid samples were taken from the gas-liquid separator and analyzed using a Perkin Elmer auto system XL equipped with a 30 m Stabilwax (Crossbond Carbowax-PEG, Restek) 0.32-mm capillary column with a $0.25-\mu \mathrm{m}$ coating.

\section{Results}

\subsection{Heat transfer in the micro-heat-exchanger}

The reaction side heat transfer coefficient, $h_{R}$, can be calculated based on the reaction side heat balance for one element:

$$
\begin{aligned}
q_{R} & =\left(T_{R, \text { in }}-T_{R, \text { out }}\right) \cdot\left(\dot{m}_{G} c_{p, G}+\dot{m}_{L} c_{p, L}\right) V_{R}^{-1} \\
& =h_{R} \cdot A_{H E X, R} \cdot \Delta T_{m, R} \cdot V_{R}^{-1}
\end{aligned}
$$

Due to the small difference between reaction side inlet and outlet temperature ( $<10 \mathrm{~K}$ for all experiments) the mean temperature gradient between HEX element and $G-L$ bulk was approximated by

$\Delta T_{m, R}=\frac{T_{R, \text { in }}+T_{R, \text { out }}}{2}-T_{\text {wall }}$

As the bulk temperature of the heat-exchange element, $T_{\text {wall }}$, was not directly accessible, it was assumed constant over the whole solid element. This simplification can be justified by the small wall thickness of the heat-exchange tubes and the high heat conductivity of the HEX material. 


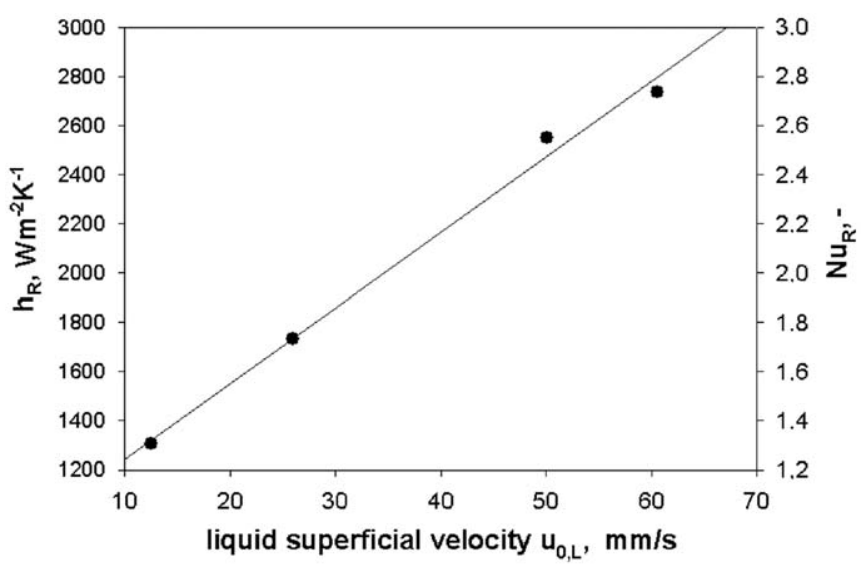

Fig. 6. Reaction side heat transfer coefficient and $N u_{R}$ for different liquid superficial velocities for single-phase flow (water).

In analogy to $\Delta T_{m, R}$, the cooling water side mean temperature difference, $\Delta T_{m, C W}$, was approximated by the linear expression

$\Delta T_{m, C W}=T_{\text {wall }}-\frac{T_{C W, \text { in }}+T_{C W, \text { out }}}{2}$

Based on this, $T_{\text {wall }}$ was calculated from the cooling water side heat balance shown in Eq. (4), using the heat flow into the reaction mixture from the reaction side heat balance shown in Eq. (1):

$q_{C W}=N u_{C W} \frac{\lambda_{C W}}{d_{C h, C W}} \cdot A_{H E X, C W} \cdot \Delta T_{m, C W} \cdot V_{R}^{-1}$

To calculate the Nusselt number for the cooling water channels the relationship given by Gnielinski (1976) (Eq. (5)) was used. The cooling water channel Reynolds number was $\operatorname{Re}=3600$, based on the dynamic viscosity of $1.3 \times 10^{-3}$ Pa s (water at $10^{\circ} \mathrm{C}$ ) and a flow velocity of $5.9 \mathrm{~m} \mathrm{~s}^{-1}$ :

$N u=\frac{\xi / 8(R e-1000) \operatorname{Pr}}{1+12.7 \sqrt{\xi / 8}\left(\operatorname{Pr}^{2 / 3}-1\right)}\left(1+\left(\frac{d_{h}}{l}\right)^{2 / 3}\right)\left(\operatorname{Pr}_{\text {fluid }} / \operatorname{Pr}_{\text {wall }}\right)^{0.11}$

with $\xi=\left(1.8 \log _{10}(\mathrm{Re})-1.5\right)^{-2}$.

All calculations were based on the heat transfer area of tubes protruding into the reactor volume only. Residual heat transfer, especially through the HEX bulk to the cooling water distribution volumes can clearly not be excluded, but had nevertheless to be neglected for the heat transfer calculations.

\subsubsection{Single-phase heat transfer: water}

Fig. 6 shows the heat transfer coefficient obtained for pure water, determined without catalyst. It can be seen that heat transfer increases linearly with liquid flow velocity over the whole experimental range. These results confirm the findings of several studies of heat transfer in micro-channels at low Re-values (e.g. Wu and Cheng, 2003). It has to be noted, that the above mentioned study was done for fully developed laminar flow. However, for the short heat transfer slits studied in the present work, this is not the case. Due to the small ratio of slit height to hydraulic diameter of $\sim 11.75$, a large part of the channel length has to be considered as entrance region with nondeveloped laminar flow pattern. This explains the high values of $N u_{R}$ at low Re between $1.12 \times 10^{-5}$ and $5.45 \times 10^{-5}$.

\subsubsection{Two-phase heat transfer: water/air}

The influence of the addition of gas on the reaction side heat transfer coefficient was tested using the system water/air over the gas and liquid superficial velocity range given in Table 2 .

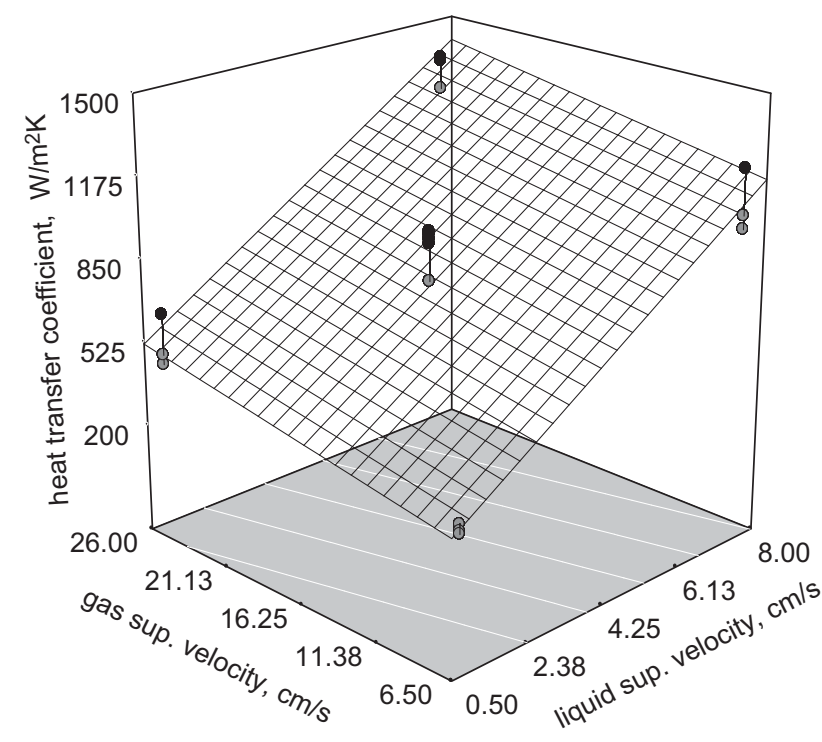

Fig. 7. Reaction side heat transfer coefficient for different gas and liquid superficial velocities in the HEX slits for the system water-air with one layer of SMF catalyst. Experimental data $(\bullet)$ and linear model (grid).

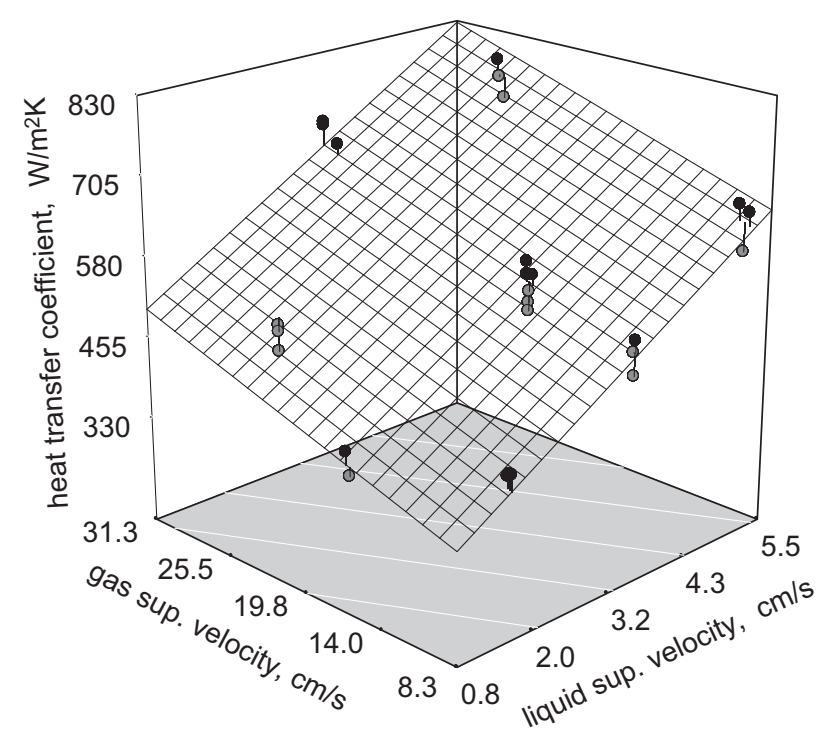

Fig. 8. Reaction side heat transfer coefficient for different gas and liquid superficial velocities in the HEX slits for the system MBY-N2 with one layer of SMF catalyst. Experimental data $(\bullet)$ and linear model (grid).

One layer of fibrous catalyst is placed between reactor inlet and heat-exchange element. The ANOVA analysis confirmed the linear dependence of the heat transfer on gas and liquid velocities apparent in Fig. 7, the model equation is given as follows:

$h_{R}=164.7+116 \cdot u_{0, L}+11.8 \cdot u_{0, G}$

The validity of Eq. (6) is limited to the experimental domain shown in Fig. 7.

\subsubsection{Two-phase heat transfer: organic solvent $/ \mathrm{N}_{2}$}

To simulate actual reaction conditions, the two-phase experimental program including one layer of catalyst was repeated using 2methyl-3-butyn-2-ol and nitrogen as reaction side fluids. The results are shown in Fig. 8. The ANOVA data analysis confirms the linear 


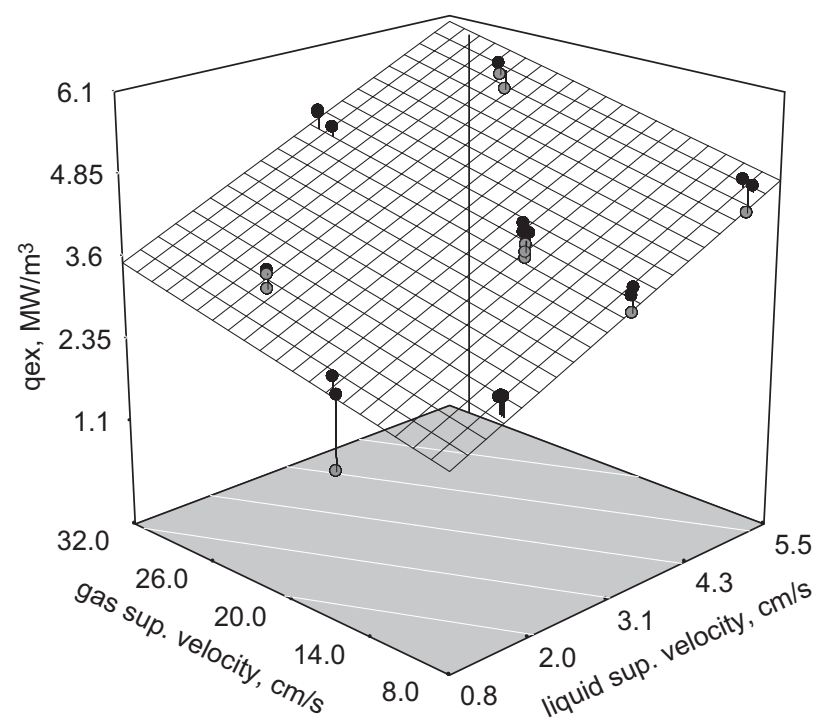

Fig. 9. Heat transfer performance of the SBCR $(\Delta T m=10 \mathrm{~K})$.

dependence of heat transfer on fluid velocities as well as the absence of any interaction effect measured for the system water-air. The resulting linear model shown in Fig. 8 can be written as

$h_{R}=218.6+66.9 \cdot u_{0, L}+7.2 \cdot u_{0, G}$

It can be seen that the heat transfer decreases considerably when switching from water to organic solvent. This could be expected due to the lower thermal conductivity and higher viscosity of MBY (see Table 3) affecting the heat transfer.

Based on these heat transfer characteristics, the heat transfer performance per free volume of a SBCR with integrated cooling stages can be determined by

$q_{e x}=\left(\frac{1}{h_{R} A_{R}}+\frac{1}{h_{C W} A_{C W}}\right)^{-1} \frac{\Delta T_{m}}{V_{R}}$

The performance as calculated for $\Delta T_{m}$ of $10 \mathrm{~K}$ is shown in Fig. 9 .

The linear dependence on $u_{0, G}$ and $u_{0, L}$ is preserved from the primary heat transfer results shown in Fig. 8 . It can be seen that even for the moderate upper boundaries of the experimental flow velocity range, a specific heat transfer performance of $q_{e x} \approx 6 \mathrm{MW} \mathrm{m}^{-3}$ can be achieved.

\subsection{SBCR performance in a three-phase solvent free hydrogenation}

The solvent free hydrogenation of 2-methyl-3-butyn-2-ol to 2methyl-3-buten-2-ol was used as a model reaction (Fig. 1) to evaluate the performance of the SBCR.

In preliminary studies the $\mathrm{Pd} / \mathrm{ZnO} / \mathrm{SMF}$ catalyst was optimized and the intrinsic reaction kinetics was determined in a batch-wise operated autoclave (Semagina et al., 2007, 2008; Crespo-Quesada et al., 2008). High MBE selectivity of $98 \%$ up to $99 \%$ MBY conversion could be obtained.

The intrinsic kinetics was well described by a simplified Langmuir-Hinshelwood model assuming competitive adsorption of the reactants on one type of active site and bimolecular reactions of the adsorbed species (Semagina et al., 2008). In addition, the reaction rate was found to be of 1 st order to hydrogen. Because the adsorption equilibrium constants of the products are small compared to the adsorption constant of the acetylenic alcohol $\left(K_{M B Y}\right)$, they can be approximated by a common adsorption constant $\left(K_{\mathrm{Pr}}\right)$ and a final rate equation results:

$r_{1}=\frac{k^{\prime} c_{0, M B Y} \cdot(1-X)}{\left(1+K_{M B Y} c_{0, M B Y}(1-X)+K_{\operatorname{Pr}} c_{0, M B Y} X\right)} \cdot c_{H_{2}}$

where $k_{1}^{\prime}$ is a lumped rate constant and $c_{H_{2}}$ is the concentration of dissolved hydrogen.

The hydrogenation reaction was carried out in SBCR with one and three stages under different temperatures, $\mathrm{H}_{2}$-pressures and flow rates as summarized in Table 4. After each run in the SBCR, the intrinsic activity of the used catalyst was checked in a stirred autoclave under identical reaction conditions. A particular attention concerned the avoidance of any mass transfer resistance, as the liquid reactant mixture must be always saturated with hydrogen $\left(c_{\mathrm{H}_{2}}=\mathrm{C}_{\mathrm{H}_{2}}^{*}\right)$ at the corresponding temperature and pressure. This was controlled by on-line analysis of the dissolved hydrogen in the operating reactor (Meyberg and Roessler, 2005; Bruehwiler et al., 2008). In this way, the experiments allowed to determine the maximal catalyst performance at the same conversions as obtained in the SBCR. In Table 4 the corresponding values are given for each experiment.

It turned out that the observed specific catalyst performance in the SBCR is significantly lower compared to the maximum obtainable in the kinetic regime. As the specific catalyst concentration is about 1-2 order of magnitude higher than in the autoclave, it can be assumed that a depletion of hydrogen in the liquid phase leads to the observed performance drop. As the reaction rate is proportional to the concentration of dissolved hydrogen, the hydrogen concentration can be related to the observed effectiveness factor, $\eta$.

$\eta=\frac{-R_{M B Y, e f f}}{-R_{M B Y, \max }}=\frac{k_{v}^{\prime \prime} \cdot c_{\mathrm{H}_{2}}}{k_{v}^{\prime \prime} \cdot c_{\mathrm{H}_{2}}^{*}}=\frac{c_{\mathrm{H}_{2}}}{c_{\mathrm{H}_{2}}^{*}}$

where $k_{v}^{\prime \prime}$ is a lumped parameter obtained for the used reaction conditions and identical conversion.

The measured effective transformation rate referred to the free volume of the SBCR allows to estimate the gas/liquid volumetric mass transfer coefficient based on the molar hydrogen balance around the reactor.

$k_{L} a\left(c_{H_{2}}^{*}-c_{H_{2}}\right)-R_{e f f}=\frac{Q_{L, r e c}}{V_{R}}\left(c_{H_{2}}^{*}-c_{H_{2}}\right)$

with : $R_{\text {eff }}=R_{M B Y, e f f}=R_{\mathrm{H}_{2}, \text { eff }}$

$k_{L} a=\frac{R_{e f f}}{c_{H_{2}}^{*}(1-\eta)}-\frac{Q_{L, r e c}}{V_{R}}$

As a result, a volumetric mass transfer coefficient of $k_{L} a=1.2 \pm$ $0.15 \mathrm{~s}^{-1}$ is obtained, which is in-line with results obtained in a bubble column staged with glass fiber fabrics. The experimental results are compared with predictions based on the efficiency of a first order reaction as function of the second Damköhler number (Fig. 10):

DaII $=\frac{k_{v}^{\prime \prime}}{k_{L} a}$

For initial reaction conditions Crespo-Quesada et al. (2008) proposed a simplified kinetic model for the MBY hydrogenation:

$r_{0,1}=k_{r} \cdot c_{H_{2}}=A \cdot \exp \left(\frac{-E_{a}}{R \cdot T}\right) c_{H_{2}}$

They estimated the reaction parameters as follows:

$A=8.96 \times 10^{3} \pm 2 \% \mathrm{~m}^{3} \mathrm{~mol}_{P d}^{-1} \mathrm{~s}^{-1} ; \quad E_{a}=25.3 \pm 1.6 \% \mathrm{~kJ} \mathrm{~mol}^{-1}$

Here $k_{r}$ is a global constant including the surface rate constant and the adsorption constants. The global rate constant contains also the 
Table 4

Reaction conditions and results for SBCR hydrogenation runs.

\begin{tabular}{|c|c|c|c|c|c|c|}
\hline \multirow[t]{2}{*}{$\begin{array}{l}\text { Reaction } \\
\text { pressure } p_{R} \text { (Mpa) }\end{array}$} & \multirow[t]{2}{*}{$\begin{array}{l}\text { Reaction } \\
\text { temperature } T_{R}(\mathrm{~K})\end{array}$} & \multicolumn{2}{|c|}{$\begin{array}{l}\text { Recycle flow rate } \\
Q_{\text {rec }}\left(\mathrm{m}^{3} \mathrm{~s}^{-1}\right)\end{array}$} & \multirow[t]{2}{*}{$\begin{array}{l}\text { Measured rate } \\
r_{\text {eff }}\left(\mathrm{mol} \mathrm{mol}_{P d}^{-1} \mathrm{~s}^{-1}\right)\end{array}$} & \multirow[t]{2}{*}{$\begin{array}{l}\text { Catalyst } \\
\text { efficiency (\%) }\end{array}$} & \multirow[t]{2}{*}{$\begin{array}{l}\text { MBY conversion } \\
\text { (dimentionless) }\end{array}$} \\
\hline & & Gas & Liquid & & & \\
\hline 0.2 & 343 & $2.3 \times 10^{-5}$ & $3.3 \times 10^{-6}$ & 2.11 & 35.6 & 0.22 \\
\hline 0.37 & 323 & $2.3 \times 10^{-5}$ & $3.3 \times 10^{-6}$ & 4.83 & 56.6 & 0.48 \\
\hline 0.67 & 308 & $2.3 \times 10^{-5}$ & $3.3 \times 10^{-6}$ & 5.51 & 55.0 & 0.32 \\
\hline 0.4 & 338 & $3.1 \times 10^{-5}$ & $6.8 \times 10^{-6}$ & 4.66 & 39.60 & 0.39 \\
\hline 0.4 & 338 & $7.2 \times 10^{-5}$ & $6.8 \times 10^{-6}$ & 4.56 & 38.74 & 0.41 \\
\hline 0.4 & 338 & $5.5 \times 10^{-6}$ & $6.8 \times 10^{-6}$ & 4.54 & 38.60 & 0.39 \\
\hline 0.4 & 338 & $3.1 \times 10^{-5}$ & $1.8 \times 10^{-6}$ & 4.39 & 37.25 & 0.35 \\
\hline 0.4 & 338 & $9.8 \times 10^{-6}$ & $1.8 \times 10^{-6}$ & 4.23 & 35.93 & 0.42 \\
\hline
\end{tabular}

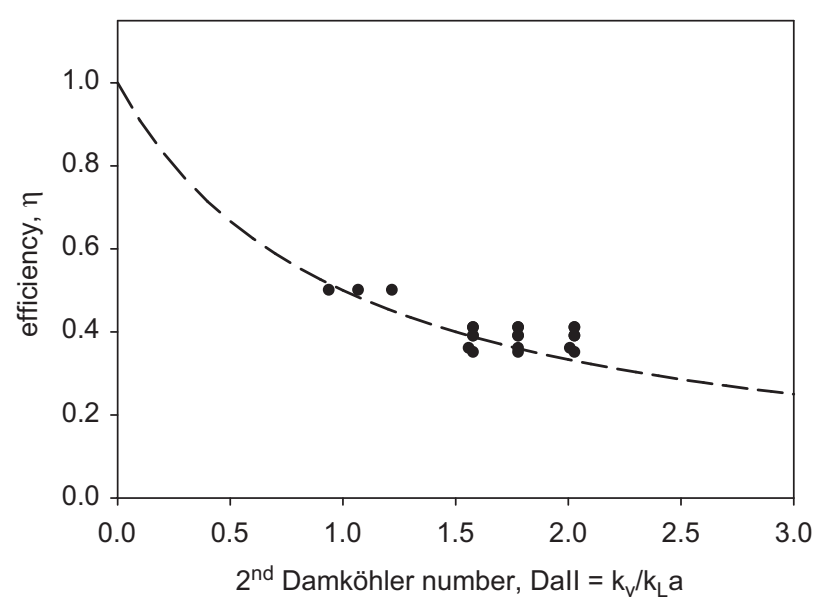

Fig. 10. Predicted and measured effectiveness factor as function of the 2nd Damköhler number.

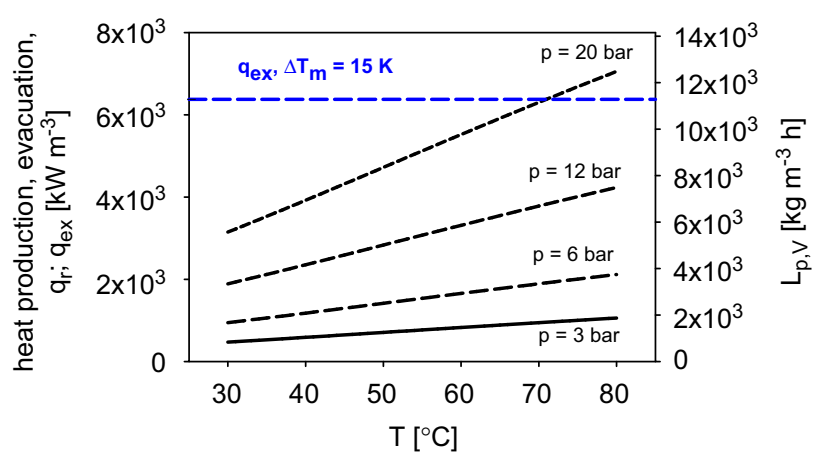

Fig. 11. Specific performance of the staged bubble column reactor and heat production as function of temperature and hydrogen pressure.

initial concentration of $\operatorname{MBY}\left(C_{0, M B Y}=10 \mathrm{kmol} \mathrm{m}^{-3}\right)$. Under the reaction conditions used for the batch reaction, the hydrogen concentration in MBY corresponds to the saturation concentration $\left(\mathrm{C}_{\mathrm{H}_{2}}=\mathrm{C}_{\mathrm{H}_{2}}^{*}\right.$ ).

Eq. (14) can be used to predict the specific performance of SBCR as a function of the reaction temperature and pressure, taking into account the gas/liquid mass transfer resistance.

$L_{P, V}=r_{0,1} \cdot \frac{m_{\text {cat }}}{V_{R}} \cdot \eta ; \quad$ with $\eta=\frac{1}{1+\text { Dall }}$
The results are shown in Fig. 11 together with the heat production $q_{r}$ and the heat evacuation.

$$
\begin{aligned}
q_{r} & =r_{0,1} \cdot \frac{m_{\text {cat }}}{V_{R}} \cdot \eta \cdot\left(-\Delta H_{R}\right) \\
& =L_{P, V} \cdot\left(-\Delta H_{R}\right) ; \quad \text { with }:-\Delta H_{R}=170 \mathrm{~kJ} \mathrm{~mol}^{-1}
\end{aligned}
$$

The heat evacuation $q_{e x}$ is calculated with Eq. (8) for $Q_{G}=1.400 \times$ $10^{-3} \mathrm{~m}^{3} \mathrm{~min}^{-1}$ and $Q_{L}=0.2 \times 10^{-3} \mathrm{~m}^{3} \mathrm{~min}^{-1}$, based on a mean temperature difference between reaction mixture and cooling medium of $\Delta T_{m}=15 \mathrm{~K}$. The operating region of the SBCR lies under the horizontal line in Fig. 11 signifying $q_{e x}$, where $q_{e x} \geq q_{r}$ and the produced reaction heat can be fully evacuated.

It can be seen that despite the influence of external mass transfer effects on the reaction the predicted reactor performance for MBE production can be attained up to ca. $12,000 \mathrm{~kg} \mathrm{~m}^{-3} \mathrm{~h}^{-1}$ depending on pressure and temperature even at moderate temperature differences in the micro-structured heat-exchanger. This corresponds to a process intensification of two orders of magnitude as compared to a standard batch slurry reactor with a typical specific productivity of $\sim 125 \mathrm{~kg} \mathrm{~m}^{-3} \mathrm{~h}^{-1}$.

\section{Conclusions}

A novel cross flow micro-heat-exchangers (HEX) integrated in a bubble column staged by structured catalytic layers was designed and tested in the solvent free hydrogenation of 2-methyl-3-butyn2-ol. The micro-HEX was designed as vertical micro-slits on the reaction side and horizontal cooling water channels, combining high specific heat transfer area and short heat transfer lengths with a minimum of added reactor volume. CFD simulations of the cooling water system confirm even fluid distribution between the cooling channels under turbulent conditions.

For both single- and two-phase conditions the reaction side heat transfer in the HEX elements was found to increase linearly with gas and liquid superficial velocity $u_{0, G}$ and $u_{0, L}$, respectively. Change from water to organic media decreased heat transfer in the HEX element and the influence of $u_{0, G}$ and $u_{0, L}$ diminished. A volumetric heat transfer performance for two-phase flow up to $\sim 12,000 \mathrm{~W} \mathrm{~m}^{-3} \mathrm{~K}^{-1}$ was achieved even for moderate gas and liquid superficial velocities.

The micro-HEX integrated within SBCR with catalytic layers made of $\mathrm{Pd} / \mathrm{ZnO} / \mathrm{SMF}$ showed high specific productivity in a solvent free hydrogenation of MBY under isothermal conditions. The observed low catalyst effectiveness between $35 \%$ and $55 \%$ were interpreted as an effect of gas-liquid mass transfer limitation due to high catalyst density. The volumetric mass transfer coefficient, $k_{L} a$, was estimated as $\sim 1.2 \mathrm{~s}^{-1}$, a value considerably higher than those obtained in conventional packed bed or slurry reactors.

The attained specific reactor performance was found to be several orders of magnitude above the values reported for conventional multiphase reactors. Adjusting the hydrogen partial pressure can 
increase the productivity up to the limits governed by the heat transfer performance of the HEX element. Thus, the SBCR with integrated micro-HEX is suitable design for continuous multiphase hydrogenation leading to significant process intensification.

\section{Notation}

\begin{tabular}{|c|c|}
\hline \multicolumn{2}{|l|}{ Symbols } \\
\hline$A$ & heat transfer area, $\mathrm{m}^{2}$ \\
\hline$c_{p}$ & Specific heat capacity, $\mathrm{J} \mathrm{kg}^{-1} \mathrm{~K}^{-1}$ \\
\hline$d$ & diameter, m \\
\hline$D_{\mathrm{SBCR}}$ & internal bubble column diameter, $\mathrm{m}$ \\
\hline DaII & 2nd Damköhler number, dimentionless \\
\hline$E_{a}$ & activation energy, $\mathrm{kJ} \mathrm{mol}^{-1}$ \\
\hline$h$ & heat transfer coefficient, $\mathrm{W} \mathrm{m}^{-2} \mathrm{~K}^{-1}$ \\
\hline$\Delta H_{R}$ & molar heat of reaction, $\mathrm{kJ} \mathrm{mol}^{-1}$ \\
\hline$k_{v}^{\prime \prime}$ & lumped volumetric rate constant, $\mathrm{s}^{-1}$ \\
\hline$k^{\prime}$ & lumped rate constant, $\mathrm{m}^{6} \mathrm{~mol}_{P d}^{-1} \mathrm{~mol}^{-1} \mathrm{~s}^{-1}$ \\
\hline$k_{L} a$ & gas/liquid volumetric mass transfer coefficient, $\mathrm{s}^{-1}$ \\
\hline$k_{r}$ & rate constant, $\mathrm{m}^{3} \mathrm{~mol}_{P d}^{-1} \mathrm{~s}^{-1}$ \\
\hline$K$ & adsorption constant, $\mathrm{m}^{3} \mathrm{~mol}^{-1}$ \\
\hline$l$ & cooling channel/slit length, m \\
\hline$L_{P, V}$ & volumetric reactor performance, $\mathrm{kg} \mathrm{m}^{-3} \mathrm{~h}^{-1}$ \\
\hline$m_{\text {cat }}$ & catalyst mass, $\mathrm{kg}$ \\
\hline$\dot{m}$ & mass flow, $\mathrm{kg} \mathrm{s}^{-1}$ \\
\hline$M$ & molar mass, $\mathrm{g} \mathrm{mol}^{-1}$ \\
\hline$N$ & number of cooling slits, dimentionless \\
\hline $\mathrm{Nu}$ & Nusselt number, dimentionless \\
\hline$p$ & pressure, Pa \\
\hline $\operatorname{Pr}$ & Prandtl number, dimentionless \\
\hline$q_{e x}$ & volumetric heat evacuation, $\mathrm{W} \mathrm{m}^{-3}$ \\
\hline$q_{r}$ & volumetric heat production, $\mathrm{W} \mathrm{m}^{-3}$ \\
\hline$Q$ & volumetric flow rate, $\mathrm{m}^{3} \mathrm{~s}^{-1}$ \\
\hline$r$ & reaction rate, $\mathrm{mol} \mathrm{mol}_{P d}^{-1} \mathrm{~s}^{-1}$ \\
\hline$R$ & volumetric production rate, $\mathrm{mol} \mathrm{m}^{-3} \mathrm{~s}^{-1}$ \\
\hline $\operatorname{Re}$ & Reynolds number, dimentionless \\
\hline$\Delta T_{m}$ & mean temperature difference, $\mathrm{K}$ \\
\hline$T$ & temperature, $\mathrm{K}$ \\
\hline$u_{0}$ & superficial velocity, reaction side \\
\hline$V$ & volume, $\mathrm{m}^{3}$ \\
\hline$X$ & Conversion, dimentionless \\
\hline
\end{tabular}

\section{Greek letters}

$\begin{array}{ll}\lambda & \text { heat conductivity, } \mathrm{W} \mathrm{m}^{-1} \mathrm{~K}^{-1} \\ \eta & \text { catalyst efficiency, dimentionless }\end{array}$

\section{Indices and abbreviations}

ANOVA analysis of variance, from Box et al. (2005)

CW cooling water

eff effective

G gas

HEX heat-exchanger

$\begin{array}{ll}L & \text { liquid } \\ \max & \text { maximum, intrinsic } \\ \mathrm{Pr} & \text { product } \\ \text { react } & \text { reactant } \\ \text { rec } & \text { recycle } \\ R & \text { reaction side } \\ \text { SMF } & \text { sintered metal filters } \\ \text { tot } & \text { total } \\ \text { wall } & \text { HEX element wall } \\ 0 & \text { initial conditions }\end{array}$

\section{Acknowledgments}

The financial support from the Swiss National Science Foundation and the Swiss Innovation Promotion Agency (CTI) is gratefully acknowledged. The authors thank Akash Gupta for participation in CFD simulation.

\section{References}

Box, G.E.P., Hunter, S.J., Hunter, W.G., 2005. Statistics for Experimenters. second ed. Wiley, Hoboken, NJ.

Bruehwiler, A., Semagina, N., Grasemann, M., Renken, A., Kiwi-Minsker, L., Saaler, A. Lehmann, H., Bonrath, W., Roessler, F., 2008. Three-phase catalytic hydrogenation of a functionalized alkyne: mass transfer and kinetic studies with in situ hydrogen monitoring. Industrial \& Engineering Chemistry Research 47 (18), 6862-6869.

Crespo-Quesada, M., Grasemann, M., Semagina, N., Renken, A., Kiwi-Minsker, L., 2008. Kinetics of the solvent-free hydrogenation of 2-methyl-3-butyn2-ol over a structured Pd-based catalyst. Catalysis Today, in press, doi:10.1016/j.cattod.2008.09.035

Cybulski, A., Stankiewicz, A., Albers, R.K.E., Moulijn, J.A., 1999. Monolithic reactors for fine chemicals industries: a comparative analysis of a monolithic reactor and a mechanically agitated slurry reactor. Chemical Engineering Science 54 (13-14), 2351-2358.

Gnielinski, V., 1976. New equations for heat and mass transfer in turbulent pipe and channel flow. International Chemical Engineering 16 (359-368),

Grasemann, M., Semagina, N., Renken, A., Kiwi-Minsker, L., 2007. Hydrodynamics of a bubble column reactor staged with sintered metal fiber catalyst for continuous three-phase hydrogenation. Industrial \& Engineering Chemistry Research 46, 8602-8606.

Höller, V., Radevik, K., Kiwi-Minsker, L., Renken, A., 2001. Bubble columns staged with structured fibrous catalytic layers: residence time distribution and mass transfer. Industrial \& Engineering Chemistry Research 40 (6), 1575-1579.

Kiwi-Minsker, L., Joannet, E., Renken, A., 2004. Loop reactor staged with structured fibrous catalytic layers for liquid-phase hydrogenations. Chemical Engineering Science 59 (22-23), 4919-4925.

Kreutzer, M.T., Kapteijn, F., Moulijn, J.A., 2006. Shouldn't catalysts shape up? Structured reactors in general and gas-liquid monolith reactors in particular. Catalysis Today 111 (1-2), 111-118.

Meyberg, M., Roessler, F., 2005. In situ measurement of steady-state hydrogen concentrations during a hydrogenation reaction in a gas-inducing stirred slurry reactor. Industrial \& Engineering Chemistry Research 44 (25), 9705-9711.

Nijhuis, T.A., Kreutzer, M.T., Romijn, A.C.J., Kapteijn, F., Moulijn, J.A., 2001. Monolithic catalysts as more efficient three-phase reactors. Catalysis Today $66(2-4)$ 157-165.

Roessler, F., 2003. Catalytic hydrogenation in the liquid phase. Chimia 57 (12) 791-798.

Semagina, N., Grasemann, M., Xanthopoulos, N., Renken, A., Kiwi-Minsker, L., 2007. Structured catalyst of Pd/ZnO on sintered metal fibers for 2-methyl-3-butyn-2-ol selective hydrogenation. Journal of Catalysis 251, 213-222.

Semagina, N., Grasemann, M., Xanthopoulos, N., Renken, A., Kiwi-Minsker, L., 2008 Erratum: structured catalyst of $\mathrm{Pd} / \mathrm{ZnO}$ on sintered metal fibers for 2-methyl-3butyn-2-ol selective hydrogenation (vol. 251, p. 213, 2007). Journal of Catalysis $255,138$.

Wu, H.Y., Cheng, P., 2003. An experimental study of convective heat transfer in silicon microchannels with different surface conditions. International Journal of Heat and Mass Transfer 46 (14), 2547-2556. 